\title{
Posture-based Morphological Deformation of the Parotid Gland and its Clinical Implications for Minimally Invasive Procedures
}

Hyun Jin Park

Division in Anatomy and Developmental Biology, Department of Oral Biology, Human Identification

Research Institute, BK21 FOUR Project, Yonsei University College of Dentistry, Seoul

\section{Sung Ok Hong}

Department of Oral and Maxillofacial Surgery, Kyung Hee University Dental Hospital at Gangdong, Seoul

Hyung-Moon Kim

Maylin clinic, Gyeonggi

Wook Oh

Maylin clinic, Seoul

Hee-Jin Kim ( $\nabla$ hjk776@yuhs.ac)

Division in Anatomy and Developmental Biology, Department of Oral Biology, Human Identification Research Institute, BK21 FOUR Project, Yonsei University College of Dentistry, Seoul

\section{Research Article}

Keywords: Parotid gland, parotid gland tail, anatomical location, minimally invasive procedures

Posted Date: September 30th, 2021

DOI: https://doi.org/10.21203/rs.3.rs-860496/v1

License: (9) (1) This work is licensed under a Creative Commons Attribution 4.0 International License.

Read Full License 


\section{Abstract}

Anatomical studies of the parotid gland are important for mid- and lower face filler, botulinum toxin, and thread lifting procedures. The purpose of this study was to observe the topographic anatomy of the parotid gland using cadaveric dissections.

The superficial lobe of the parotid gland was studied in 30 hemisected heads. Reference lines were made on the lateral aspect of the face. A reference line (the line connecting the mandibular angle to the upper margin of the zygomatic arch, along the posterior margin of the ramus) was divided into four sections (P1, P2, P3, and P4). The superior, inferior, anterior, and posterior borders of the parotid gland were measured using the reference lines and sections. Using these measurements, we categorized the superficial lobe of the parotid gland into two types: type la, pistol-shaped; Ib, pistol-shaped with an accessory lobe; and type II, oval-shaped.

The superior border of the parotid gland started just below the inferior margin of the zygomatic arch. The parotid gland covered the posterior part of the masseter muscle near P1 and P2, but at P3 and below P3, the tail of the parotid gland was located posterior to the ramus and covered the anterior part of the sternocleidomastoid muscle. The topographic anatomy of the parotid gland serves as a reliable reference for esthetic procedures in the lower face and neck region.

\section{Introduction}

The parotid gland is the largest salivary gland, which is usually illustrated as a yellowish, invertedpyramid-shaped organ. It lies anteriorly and inferiorly to the external acoustic meatus, over the mandible and sternocleidomastoid muscle ${ }^{1}$. The superior border of the parotid gland runs from the mandibular condyle to the anterior border of the masseter muscle, sitting below the zygomatic arch. The anterior border of the parotid gland passes inferiorly along the masseter muscle and overlies its lateral surface. As it crosses the mandibular angle, the parotid gland tapers to a blunt apex inferiorly, which is called the tail of the parotid gland ${ }^{2}$.

The parotid gland is divided into superficial and deep lobes. The superficial lobe is covered by skin, the posterior border of the platysma, the superficial muscular aponeurotic system (SMAS), and the masseteric fascia, while the deep lobe covers the masseter and the mandible and extends beyond the mandibular ramus ${ }^{1,3}$.

Since it is important to achieve an attractive balance between the face and neck during facial rejuvenation procedures, there has been a growing interest in the morphologic characteristics and anatomical structural relationship of the parotid gland. The posterolateral jawline receives much less attention than other areas of the face; however, this area has a significant impact on jawline esthetics ${ }^{4}$. Various surgical and non-surgical procedures, such as thread lifting, botulinum toxin injection, and filler augmentation, are performed at the lateral aspect of the face as part of facial rejuvenation and esthetic 
treatment ${ }^{5-8}$. However, these procedures may result in complications, for example, one of the most dangerous complications of thread lifting is injury to the parotid gland and duct. Therefore, it is important to recognize the anatomical structures and precise layers of the lateral aspect of the face to avoid serious consequences $^{9}$.

There have been many anatomical and clinical studies on the anatomical structures of the lateral aspect of the face, such as the masseter muscle ${ }^{10,11}$, facial nerve distribution ${ }^{12,13}$, and transverse facial artery ${ }^{14}$, but only a limited number of studies have examined the anatomy of the parotid gland. Due to its close relationship with the SMAS layer, the masseter muscle, and the facial nerve, and the superficial lobe and tail of the parotid gland, it is vulnerable to injury during various minimally invasive procedures. Therefore, knowing the precise anatomical topography of the parotid gland is required to prevent complications.

In this study, we aim to determine the precise anatomical location of the superficial lobe and tail of the parotid gland through cadaveric dissections, thereby providing essential anatomical information that could be crucial during invasive and non-invasive procedures in the parotid gland region.

\section{Results}

The parotid gland was classified into two categories based on its morphology: pistol-shaped (tytpe la and Ib) and oval-shaped (type II) (Fig. 1). The pistol-shaped parotid gland was observed in $63.3 \%$ of the cases (19/30); the oval-shaped parotid gland was observed in $36.7 \%$ of the cases (11/30). An accessory parotid lobe was observed in 2 cadavers. The parotid gland in these cases was categorized as a pistol-shaped parotid gland (type lb).

The mean depths of P1, P2, and P3 from the skin to the parotid gland surface were $11.3 \pm 3.0 \mathrm{~mm}, 8.5 \pm$ $3.3 \mathrm{~mm}$, and $9.3 \pm 4.0 \mathrm{~mm}$, respectively. The mean depth of the superior border of the parotid gland was $9.8 \pm 3.2 \mathrm{~mm}$. The distances from $\mathrm{HL}$ to the superior border of the parotid gland and to the inferior margin of the zygomatic arch were 13.4 \pm 4.1 and $11.0 \pm 2.3 \mathrm{~mm}$, respectively. The distances from each point (P1 to P4) to the anterior and posterior aspects of the parotid gland are shown in Table 1 . The distance to the posterior aspect of the parotid gland, horizontally from P4 to $\mathrm{ML}$ was $31.5 \pm 6.3 \mathrm{~mm}$ and that to the inferior aspect measured vertically from P4 to ML was $13.2 \pm 4.2 \mathrm{~mm}$. Most of the parotid gland was located anterior to VL, up to P2. Below P3, the parotid gland was mainly located posterior to VL (Fig. 2). 
Table 1

Distances from the four points on $\mathrm{VL}$ to the anterior and posterior borders of the parotid gland.

\begin{tabular}{|lll|}
\hline Points & Anterior border $(\mathrm{mm})$ & Posterior border $(\mathrm{mm})$ \\
\hline P1 & $18.1 \pm 8.3$ & $2.0 \pm 5.2$ \\
\hline P2 & $25.5 \pm 9.3$ & $17.7 \pm 5.2$ \\
\hline P3 & $9.6 \pm 8.3$ & $25.4 \pm 5.6$ \\
\hline P4 & $-0.9 \pm 6.1$ & $22.0 \pm 7.7$ \\
\hline
\end{tabular}

The locations of the anterior extent of the gland and the proximal portion of the parotid duct arising from the anterior border of the parotid gland were also identified. The most anterior extent of the parotid gland was located $36.1 \pm 6.3 \mathrm{~mm}$ inferior to $\mathrm{HL}$ and $28.2 \pm 8.8 \mathrm{~mm}$ anterior to $\mathrm{VL}$. The proximal portion of the parotid duct that arose from the anterior border of the gland was $40.9 \pm 5.0 \mathrm{~mm}$ inferior to $\mathrm{HL}$ and $17.4 \pm$ $8.5 \mathrm{~mm}$ anterior to $\mathrm{VL}$.

\section{Discussion}

Several anatomical textbooks and atlases describe the morphology of the parotid gland as a wedgeshaped serous gland with an anterior-posterior length of $35 \pm 5.7 \mathrm{~mm}^{15}$ although many variations have been observed in the appearance, extent, shape, and tail of the gland during actual dissections. Recent literature and anatomy textbooks have not paid much attention to the detailed anatomy of the parotid gland and tail. In 1977, Park et al. ${ }^{16}$ classified the parotid gland into four types according to its morphology: inverted triangular shape $(66.7 \%)$, oval shape $(15.5 \%)$, inverted $L$ shape $(8.9 \%)$, and roughly triangular shape (8.9\%). The parotid tail is the most inferior portion of the superficial lobe. It is triangularly shaped and is located deep to the platysma muscle, anterolateral to the sternocleidomastoid muscle, and posterolateral to the posterior belly of the digastric muscle $\mathrm{e}^{17}$. In our study, type I, the pistol-shaped parotid gland, was observed in $63.3 \%$ of cases and type II, the oval-shape parotid gland, was observed in $36.7 \%$ of the cases. We found that the percentage and shape of the inverted triangular shape described by Park et al. are similar to those of the pistol-shaped parotid gland (type I) in our study (Fig. 1).

The description of the boundaries of the superficial lobe of the parotid gland is also different in each textbook. According to the measurements in this study, the parotid gland is located in the anterior aspect of the mandibular ramus and covers the posterior part of the masseter muscle below the zygomatic arch from the otobasion inferius. The superior border of the parotid gland was located $13.4 \pm 4.1 \mathrm{~mm}$ below $\mathrm{HL}$. Due to the large distance of the parotid gland from $\mathrm{HL}$ to the inferior border of the zygomatic arch $(11.0 \pm 2.3 \mathrm{~mm})$, if a clinician injects botulinum toxin into the lower part of the face to contour the face to be slimmer, most of the toxin may be injected into the parotid gland.

Below the otobasion inferius (between P2 and P3), the parotid gland was located at the posterior part of the ramus and angle of the mandible. Below the angle of the mandible, the parotid gland tail extended 
$13.2 \pm 4.2 \mathrm{~mm}$ inferiorly and vertically to $\mathrm{ML}$. The posterior aspect of the parotid gland, measured horizontally from $\mathrm{P} 4$ to $\mathrm{ML}$ was $31.5 \pm 6.3 \mathrm{~mm}$. This result indicated that the parotid gland tail continued to extend below the mandible and covered the anterior border of the sternocleidomastoid muscle (Fig. 3). For this reason, clinicians should be careful during thread-lifting procedures in the neck region. It is worth noting that the most anteriorly projected portion of the parotid gland extended in the direction in which the parotid duct ran.

In our study, the depth from the skin to the parotid gland surface was measured using a 3D scanner. A 3D scanning system is commonly used to estimate clinical outcomes in both invasive and non-invasive procedures involving the head and neck area. Morphological research using the 3D scanning system could provide in-depth data about the anatomical structures of the face, providing us crucial anatomical knowledge that can be used in a variety of clinical applications. The registration technique has been used to accurately determine the depth from the skin to the muscle in our previous cadaveric studies ${ }^{18-21}$.

Understanding the anatomy of the parotid gland is important and helpful when injecting mid and lowerface fillers, injecting botulinum toxin, and performing thread lifting procedures. The cadaver can be placed on the operating chair to recreate the posture that patients undergoing a procedure are positioned in. This can allow for an accurate assessment of the effect of posture during surgery on the anatomy of the parotid gland. The deformation of facial soft tissues due to change in the anatomical position is often overlooked and only a limited number of studies were conducted on this subject ${ }^{22-24}$. The facial soft tissues in the midsagittal landmarks were found to be more stable and less varied than those in the lateral aspect of the face. The displacement of the facial soft tissues due to the anatomical posture was larger toward the lateral side of the face, which includes the parotid gland. ${ }^{23}$. It is necessary to be aware of this displacement of soft tissues with the change in the anatomical position to avoid damage to the parotid gland during invasive or non-invasive procedures involving the head and neck.

The limitation of our study, we only dissected cadavers of older individuals. In an earlier study, no statistically significant difference in the size of the parotid gland was found between older and younger individuals ${ }^{15}$. To explore this further, newer studies may be necessary to assess the morphology and the displacement of the parotid gland due to body posture in younger individuals.

In conclusion, in this study we identified the location of the parotid gland and parotid tail through cadaveric dissections, thus providing topographic information that can be used as a reference for invasive and non-invasive procedures in the parotid gland region. Earlier studies have demonstrated that displacement of facial soft tissues occurs with a change in body posture. In light of this information, the results of this study can serve as a reference to surgeons when performing minimally invasive procedures in the head and neck region to avoid surgical complications.

\section{Materials \& Methods}


Thirty hemi-faces of Korean cadavers ( 19 males and 11 females, mean age 79.7 years) were used in this study. None of the cadaveric specimens had congenital malformations, pathological findings, and history of surgery or trauma. The study was conducted in accordance with the Declaration of Helsinki ethical principles for medical research involving human subjects. All authors were well-informed of the WMA Declaration of Helsinki - Ethical Principles for Medical Research Involving Human Subjects - and confirmed that the present study firmly fulfilled the declaration.

All embalmed cadavers were scanned on the frontal and bilateral sides to obtain three-dimensional (3D) images using a structured-light 3D scanner (Morpheus3D $®$, Morpheus Company, Gyeonggi, Korea). The skin, subcutaneous layer, SMAS layer, parotid masseteric fascia, and facial nerve were carefully dissected on the left half of the face. The dissected faces were scanned using the same method. Anatomical dissection and 3D scanning were performed as described by Lee et al. ${ }^{21}$. The two reconstructed 3D images were superimposed based on the undissected right side of the face and analyzed using the Morpheus Dental Solution (MDS) software 3.0 (version 3.0, Morpheus Company). The difference between the two 3D images indicated the depth of each anatomical structure under the skin. The depth of the parotid gland from the skin was determined at each point (Fig. 4).

The dimensions of the parotid gland were measured in the dissected specimens using the following reference lines on the lateral aspect of the face: horizontal line $(\mathrm{HL})$, The transverse reference line from the jugal point along the superior border of the zygomatic arch; mandible line $(\mathrm{ML})$, the line from the mandibular angle along the inferior border of the mandible; and vertical line (VL), the vertical reference line from the mandibular angle along the posterior margin of the ramus. VL was divided into four sections (P1-P4). The distance from the reference lines to the superior, inferior, anterior, and posterior borders of the parotid gland was measured at each point. Furthermore, the protruding point of the parotid gland and the point at which the parotid duct arose were measured (Fig. 5). All measurements were performed using digital calipers (CD-15APX; Mitutoyo Corporation, Japan).

\section{Declarations}

\section{Declarations}

\section{Conflict of interest}

The authors declare no conflict of interest. The funding sponsors had no role in the design of the study, in the collection, analyses, or interpretation of data; in the writing of the manuscript, and in the decision to publish the results.

\section{Author Contributions}

All authors were well informed of the WMA Declaration of Helsinki-Ethical Principles for Medical Research Involving Human Subjects-and confirmed that the present study firmly fulfilled the Declaration 
of Helsinki. None of the authors have financial or private relationships with commercial, academic, or political organizations or people that may have improperly influenced this research.

\section{Acknowledgement}

This work supported by the National Research Foundation of Korea (NRF) Grant funded by the Korea government (MEST) (No. NRF-2020R1A2B5B0100223812). The authors thank Woohyun Cho (MFA) from Ajou University Medical Center for contributing illustrations to this manuscript.

\section{References}

1. Moore, K. L., Dalley, A. F. \& Agur, A. M. R. Clinically oriented anatomy 7th ednxxviii, 1134 p(Wolters Kluwer/Lippincott Williams \& Wilkins Health, 2014).

2. Agur, A. M. R. \& Grant, J. C. B. Grant's atlas of anatomy. 13th ed. Wolters Kluwer Health/Lippincott Williams \& Wilkins; 2013:xiv, 871 p.

3. Standring, S. Gray's anatomy: the anatomical basis of clinical practice (Forty-first edition. ed. Elsevier Limited, 2016). xviii, 1562 pages.

4. Gerald O'Daniel, T. Commentary on: The Aging Parotid Gland: A Longitudinal Volumetric Study and Implications for Treatment. Aesthet Surg J. Mar, 12 (4), 415-417 https://doi.org/10.1093/asj/sjaa412 (2021).

5. Bae, H. et al. Comparison between Conventional Blind Injections and Ultrasound-Guided Injections of Botulinum Toxin Type A into the Masseter: A Clinical Trial. Toxins (Basel). Sep, 11 (9), https://doi.org/10.3390/toxins12090588 (2020).

6. Fuster Torres, M. A., Berini Aytes, L. \& Gay Escoda, C. Salivary gland application of botulinum toxin for the treatment of sialorrhea. Med Oral Patol Oral Cir Bucal. Nov, 1 (7), E511-7 (2007).

7. Graf, R., Groth, A. K., Pace, D. \& Neto, L. G. Facial rejuvenation with SMASectomy and FAME using vertical vectors. Aesthetic Plast Surg. Jul, 32 (4), 585-592 https://doi.org/10.1007/s00266-0089173-3 (2008).

8. Sulamanidze, M. \& Sulamanidze, G. Facial lifting with Aptos Methods. J Cutan Aesthet Surg. Jan, 1 (1), 7-11 https://doi.org/10.4103/0974-2077.41149 (2008).

9. Yeo, S., Lee, Y. \& Han, D. Early Complications from Absorbable Anchoring Suture Following ThreadLift for Facial Rejuvenation. Archives of Aesthetic Plastic Surgery, 02/01, 2311 https://doi.org/10.14730/aaps.2017.23.1.11 (2017).

10. Lee, H. J. et al. The Anatomical Basis of Paradoxical Masseteric Bulging after Botulinum Neurotoxin Type A Injection. Toxins (Basel). Dec, 30 (1), https://doi.org/10.3390/toxins9010014 (2016).

11. Won, S. Y. et al. Topography of the arteries supplying the masseter muscle: Using dissection and Sihler's method. Clin Anat. Apr, 25 (3), 308-313 https://doi.org/10.1002/ca.21205 (2012). 
12. Kwak, H. H. et al. Branching patterns of the facial nerve and its communication with the auriculotemporal nerve. Surg Radiol Anat. Dec, 26 (6), 494-500 https://doi.org/10.1007/s00276-0040259-6 (2004).

13. Salame, K., Ouaknine, G. E., Arensburg, B. \& Rochkind, S. Microsurgical anatomy of the facial nerve trunk. Clin Anat. Mar, 15 (2), 93-99 https://doi.org/10.1002/ca.1102 (2002).

14. Yang, H. J., Gil, Y. C. \& Lee, H. Y. Topographical anatomy of the transverse facial artery. Clin Anat. Mar, 23 (2), 168-178 https://doi.org/10.1002/ca.20880 (2010).

15. Dost, P. \& Kaiser, S. Ultrasonographic biometry in salivary glands. Ultrasound Med Biol, 23 (9), 12991303 https://doi.org/10.1016/s0301-5629(97)00152-x (1997).

16. Park, I. Y. \& Lee, M. E. A morphological study of the parotid gland and the peripheral branches of the facial nerve in Koreans. Yonsei Med J, 18 (1), 45-51 https://doi.org/10.3349/ymj.1977.18.1.45 (1977).

17. Hamilton, B. E., Salzman, K. L., Wiggins, R. H. 3, Harnsberger, H. R. \& rd, Earring lesions of the parotid tail. AJNR Am J Neuroradiol, 24 (9), 1757-1764 (Oct 2003).

18. Lee, K. W., Yoon, J. H., Kim, J. S., Hu, K. S. \& Kim, H. J. Three-dimensional topography of facial soft tissues for the safer and effective threading procedures. Clin Anat. Feb, 14, https://doi.org/10.1002/ca.23726 (2021).

19. Choi, Y. J. et al. Three-Dimensional Evaluation of the Depressor Anguli Oris and Depressor Labii Inferioris for Botulinum Toxin Injections. Aesthet Surg J. May, 18 (6), NP456-NP461 https://doi.org/10.1093/asj/sjaa083 (2021).

20. Lee, H. J., Lee, K. W., Tansatit, T. \& Kim, H. J. Three-Dimensional Territory and Depth of the Corrugator Supercilii: Application to Botulinum Neurotoxin Injection. Clin Anat. Jul, 33 (5), 795-803 https://doi.org/10.1002/ca.23507 (2020).

21. Lee, K. W., Kim, S. H., Gil, Y. C., Hu, K. S. \& Kim, H. J. Validity and reliability of a structured-light 3D scanner and an ultrasound imaging system for measurements of facial skin thickness. Clin Anat. Oct, 30 (7), 878-886 https://doi.org/10.1002/ca.22931 (2017).

22. Iblher, N., Gladilin, E. \& Stark, B. G. Soft-tissue mobility of the lower face depending on positional changes and age: a three-dimensional morphometric surface analysis. Plast Reconstr Surg. Feb, 131 (2), 372-381 https://doi.org/10.1097/PRS.0b013e318278d67c (2013).

23. Ozsoy, U., Sekerci, R. \& Ogut, E. Effect of sitting, standing, and supine body positions on facial soft tissue: detailed 3D analysis. Int J Oral Maxillofac Surg. Oct, 44 (10), 1309-1316 https://doi.org/10.1016/j.ijom.2015.06.005 (2015).

24. Okuda, I., Yoshioka, N., Shirakabe, Y. \& Akita, K. Basic analysis of facial ageing: The relationship between the superficial musculoaponeurotic system and age. Exp Dermatol. Feb, 28 (Suppl 1), 3842 https://doi.org/10.1111/exd.13827 (2019).

\section{Figures}




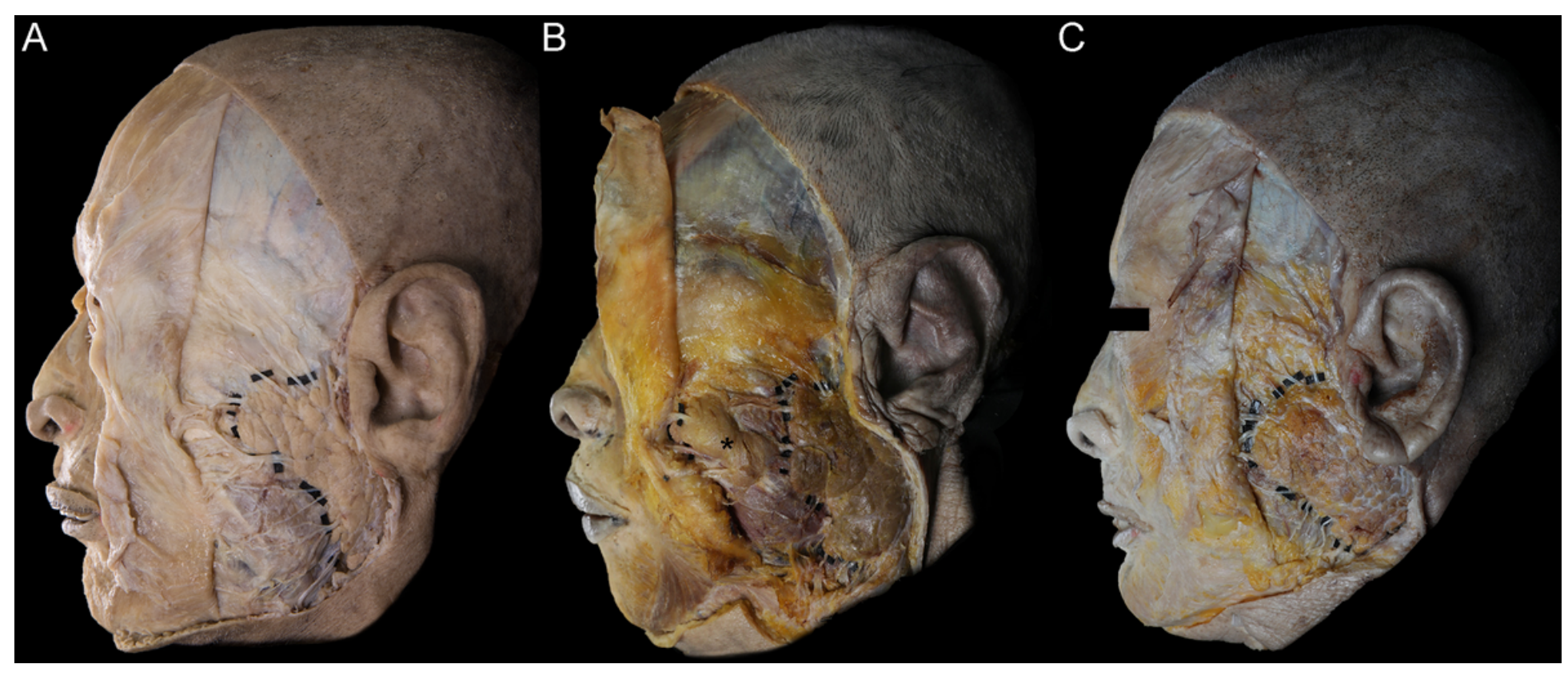

\section{Figure 1}

Photographs of specimens demonstrating the various shapes of the parotid gland. (A) Pistol-shaped parotid gland (type la), (B) Pistol-shaped parotid gland with accessory lobe (type lb) (accessory gland marked with *), (C) Oval-shaped parotid gland (type II). 


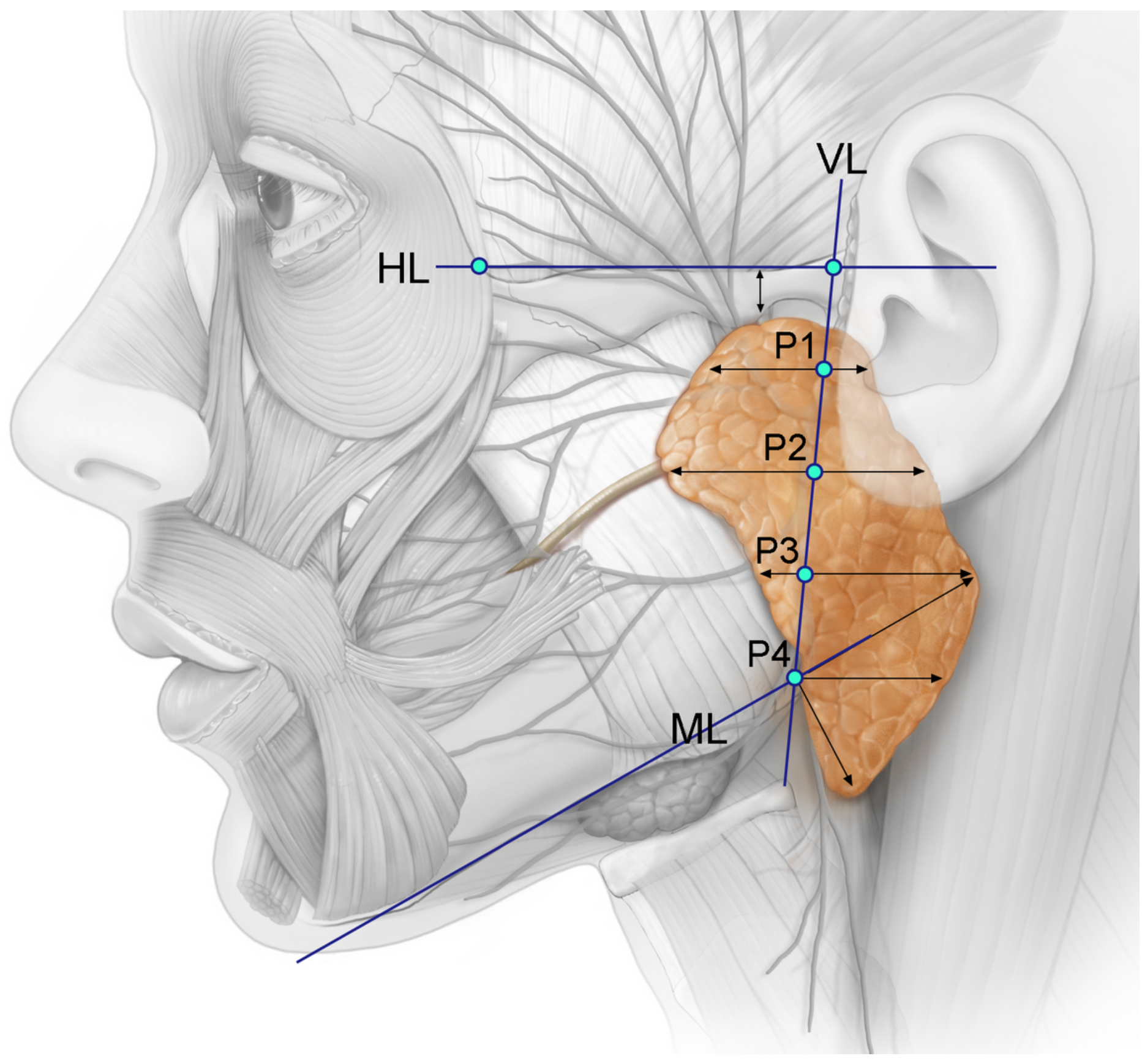

Figure 2

Illustration of the parotid gland according to the measurement results. 


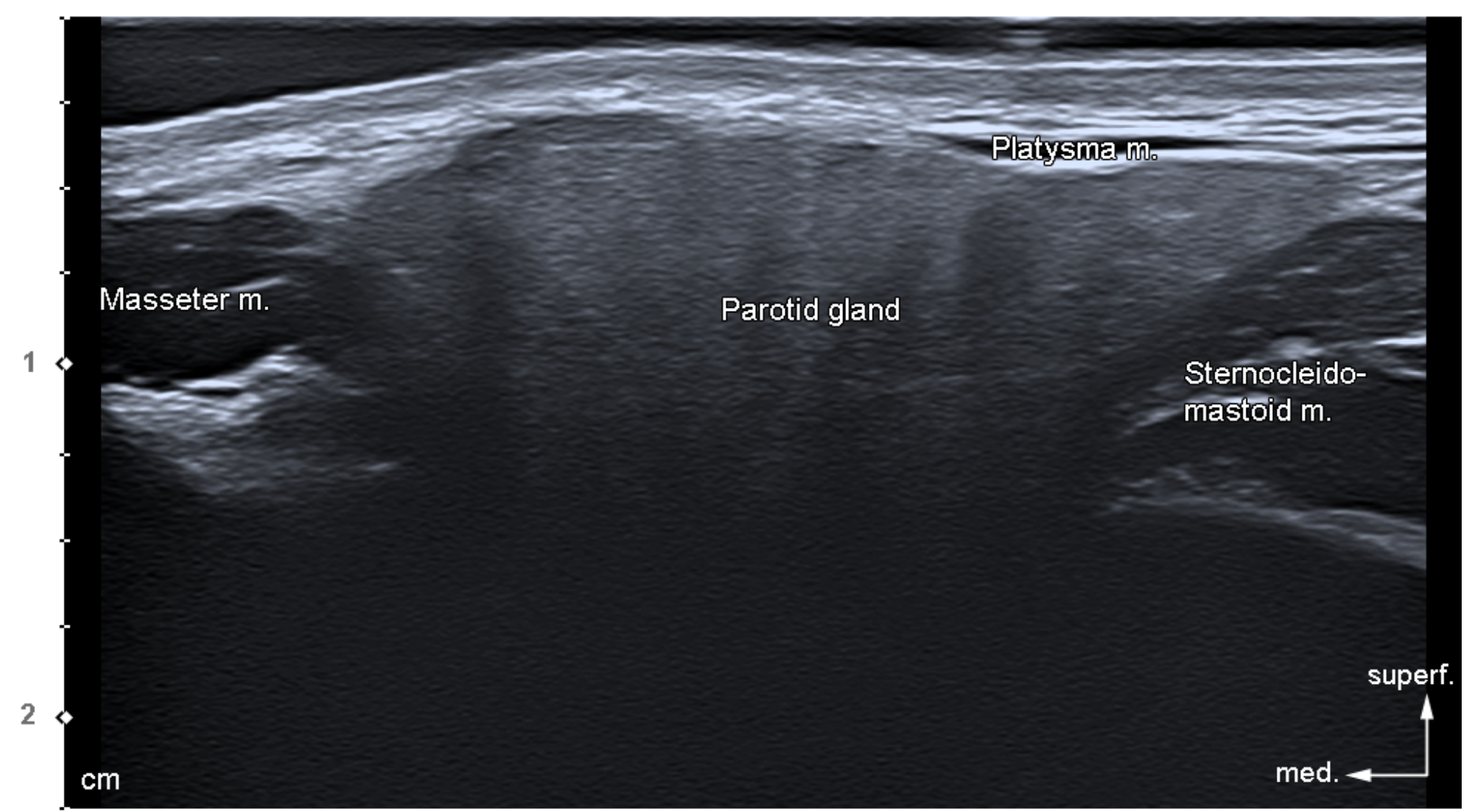

\section{Figure 3}

Ultrasonography of the mandibular angle (P4). The transducer was placed parallel to $\mathrm{ML}(18 \mathrm{MHz}$ by linear transducer; superf., superficial; med., medial).

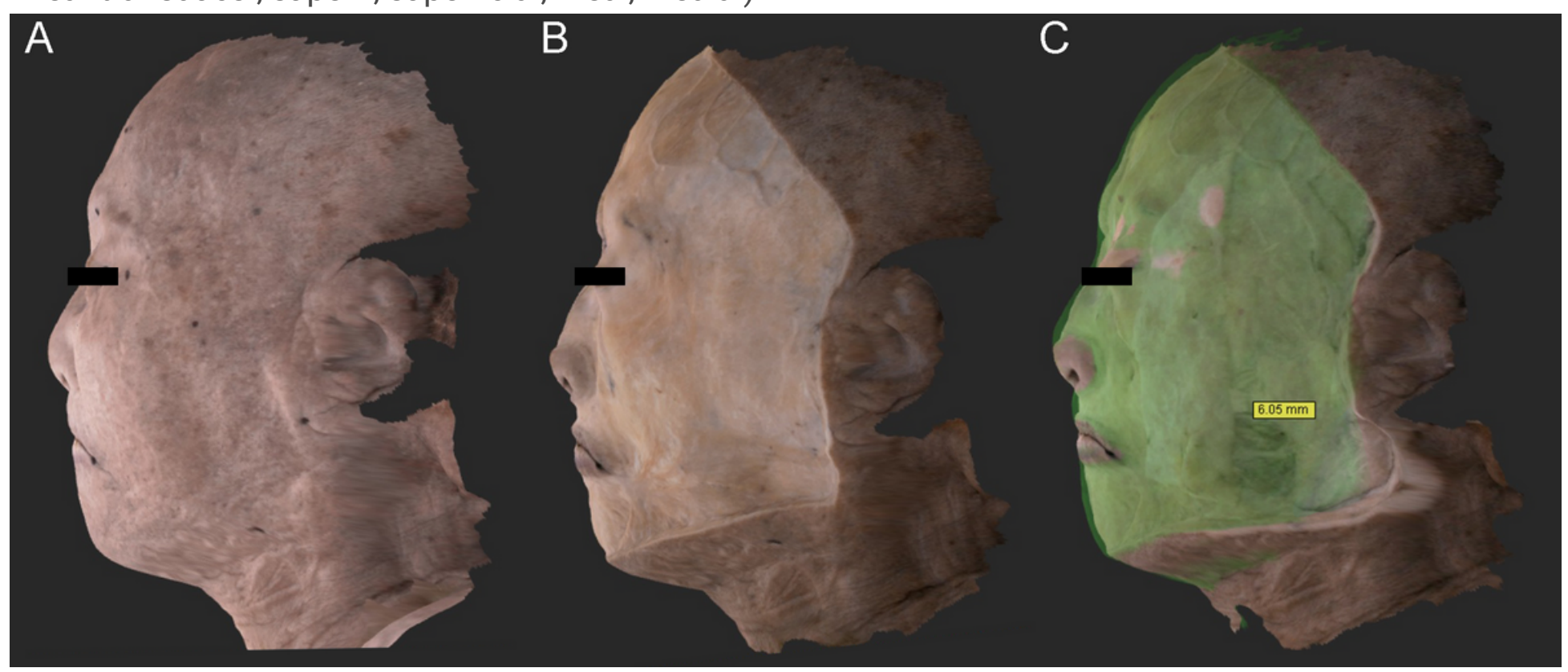

Figure 4

Superimposition of the reconstructed images of each layer using the MDS software. (A) Scanned image of the facial skin surface. (B) Scanned image of the facial muscular layer. (C) Superimposed image of the 
facial skin over the exposed parotid gland. The green area indicates the dissected area and the yellow box shown the thickness from the skin to the parotid gland surface.

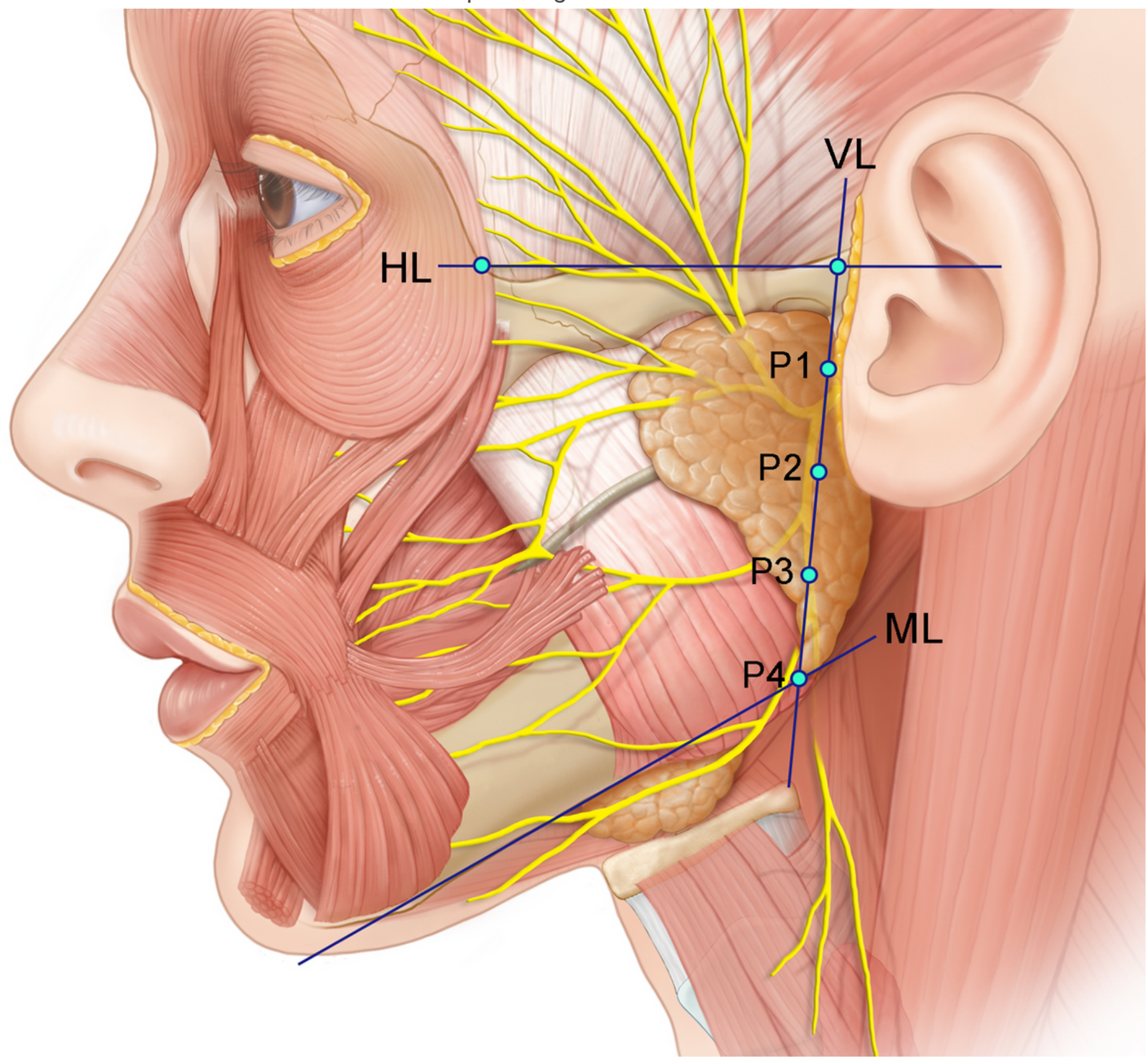

\section{Figure 5}

Diagram recreating the reference lines and points used for measuring the dimensions of the parotid gland. $V L$, posterior margin of ramus; $H L$, jugal point to $V L ; ~ M L$, inferior border of the mandible; $P 1$, point 1/4th of the distance from VL; P2, point 1/2 of the distance from VL; P3, point 3/4th of the distance from $\mathrm{VL} ; \mathrm{P} 4$, point on the mandibular angle. 